\title{
Lead Adsorption onto Various Solid Surfaces
}

\author{
Handojo Djati Utomo1,2 \\ ${ }^{1}$ School of Architecture and The Built Environment, Division of Civil Engineering, Singapore Polytechnic, \\ Singapore \\ ${ }^{2}$ Department of Chemistry, Marine and Freshwater Chemistry Laboratory, University of Otago, Dunedin, \\ New Zealand \\ Email: han@sp.edu.sg, handojo djatiutomo@yahoo.com
}

Received 12 February 2015; accepted 2 March 2015; published 9 March 2015

Copyright (C) 2015 by author and Scientific Research Publishing Inc.

This work is licensed under the Creative Commons Attribution International License (CC BY).

http://creativecommons.org/licenses/by/4.0/

(c) (i) Open Access

\begin{abstract}
Adsorption is becoming an important method in water and wastewater treatment technology at low concentrations. $\mathrm{Pb}^{2+}$ adsorption at low concentration onto various solid surfaces using either nano metal oxide of $\mathrm{MnO}_{2}$, or granulated activated carbon (GAC) or agricultural by-products such as tea leaves and coffee residue are considered promising. In this adsorption study the measurements were conducted by equilibrating Lead solutions at different concentrations range 19 - 291 $\mu \mathrm{mol} \cdot \mathrm{L}^{-1}$ with various adsorbent suspensions in the concentration range $0.388-8.738 \mathrm{~g} \cdot \mathrm{L}^{-1}$. Comparing all the adsorption capacities calculated using Langmuir equation $\mathrm{Pb}^{2+}$ adsorption by $\mathrm{MnO}_{2}$ shows the highest adsorption capacity with the estimated $\Gamma_{\mathrm{m}}=528.0 \mu \mathrm{mol} \cdot \mathrm{g}^{-1}$ at a fixed equilibrium constant $\mathrm{K}=0.0119 \mathrm{~L} \cdot \mu \mathrm{mol}^{-1}$. In addition, the $\mathrm{Pb}^{2+}$ adsorption by coffee residue is subject to a particle concentration effect in which the adsorption density decreases as the concentration of solid adsorbent $C_{s}$ is increased. The $\mathrm{Pb}^{2+}$ adsorption by tea leaves, $\mathrm{MnO}_{2}$ and GAC shows less dependency to the concentration of solid adsorbent $C_{s}$, especially at lower metal ion concentrations. In the particular case of $\mathrm{Pb}^{2+}$ adsorption on $\mathrm{MnO}_{2}$ there appears to be no dependence on $C_{s}$.
\end{abstract}

\section{Keywords}

Adsorption, Coffee Residue, GAC, $\mathrm{Pb}^{2+}$, Particle Concentration Effect, Tea Leaves, Nano Metal Oxide of $\mathrm{MnO}_{2}$

\section{Introduction}

Lead is among the most toxic heavy metal ion affecting the environment [1]. It may come into waterways through the combustion of fossil fuels and the smelting of sulphide ore, and into lakes and streams by acid mine drainage. Process industries, such as battery manufacturing and metal plating and finishing are also prime source 
of lead pollution.

Lead accumulates mainly in bones, brain, kidney and muscles and may cause many serious disorders like anaemia, kidney diseases, nervous disorders and sickness even death. In 2001, EPA published Identification of Dangerous Levels of Lead [2] and Identifying Lead Hazards in Residential Properties [3]. The World Health Organization (WHO) stated a legal limit of $50 \mathrm{ppb}$ level for lead in 1995, which is decreased to $10 \mathrm{ppb}$ level in 2010. The stringent requirement for lead in aquatic environment has triggered some wastewater engineer to work harder in searching for inexpensive material and technology to uptake lead pollutants from water and wastewater.

At low concentration of heavy metal concentration adsorption process is becoming an important pollutant removal method in water and wastewater treatment technology. After the revelation that activated carbon can adsorb organic and inorganic contaminants the advent of new technology is shifting towards sustainable technology that use more economic and environmentally friendly materials as a replacement of activated carbon.

The re-use of natural waste materials that arise through various industrial processes for additional purposes, rather than simple disposal, makes both environmental and commercial sense [4]. There also has been a recent focus on agricultural and food industry wastes such as tea, coffee grounds and rice hull as alternatives to membrane filtration, synthetic ion-exchange resins or activated carbon for treating heavy metal-containing waste waters [5] [6]. Tannin-containing materials such as exhausted coffee contain metal-binding polyhydroxy polyphenol functional groups and they are available in large quantities from the manufacture of instant coffee [4] [7]. While there have been several studies of metal ion adsorption by tea and coffee the detailed chemistry causing their affinity for different metal ions is not yet well-known [8] [9].

Adsorption of metal ions and other solutes on solid surfaces can be described by simple isotherms such as the Langmuir or Freundlich equations [9] [10]. In this approach, the extent of adsorption of lead ion $\left(\mathrm{Pb}^{2+}\right)$ per unit mass of solid adsorbent is described by simple isotherm equations that are based on conceptual models similar to those used for homogeneous equilibria. For this study the experimental data was applied to Langmuir isotherm model only due to the consistency in explaining the existence of particle concentration effect in the previous study [11]. In the Langmuir model the adsorption of a solute M by a surface S- is considered to be a result of the equilibrium surface reaction

$$
\mathrm{M}+\mathrm{S}-\leftrightarrow \mathrm{M}-\mathrm{S} \quad K=\frac{[\mathrm{M}-\mathrm{S}]}{\left[C_{e}\right] \times[\mathrm{S}-]}
$$

where $\left[\mathrm{M}-\mathrm{S}\right.$ ] is the concentration of adsorbed solute $\mathrm{M}, C_{e}$ is the concentration of unadsorbed $\mathrm{M}$ and [S-] is the concentration of free surface sites, all at equilibrium. This formalism gives rise to the Langmuir adsorption isotherm

$$
\Gamma=\Gamma_{m} \frac{K C_{e}}{\left(1+K C_{e}\right)}
$$

where $\Gamma=[\mathrm{M}-\mathrm{S}]$ is the adsorption density, i.e. the concentration of adsorbed $\mathrm{M}$ per unit mass of solid and $\Gamma_{\mathrm{m}}$ is the maximum concentration of adsorbed $\mathrm{M}$.

In Equation (2), the adsorption properties are inherently described by the equilibrium constant in Equation (1) which may be identified with the free energy of adsorption of $M$ by the solid. Normally, $K$ and $\Gamma_{m}$ may be determined simultaneously from measurements of $\Gamma$ and $C_{e}$ under different conditions.

This batch adsorption study was meant to be a comparison study set up using different concentration of adsorbents at various concentration of $\mathrm{Pb}^{2+}$. Granulated Activated Carbon (GAC) and nano metal oxide of $\mathrm{MnO}_{2}$ were used as comparisons to agricultural by-product materials of tea leaves and coffee residues.

\section{Materials and Methods}

\subsection{Chemicals}

All chemicals including $\mathrm{MnO}_{2}$ and GAC used in this study were of analytical grade obtained from Merck, Germany. Stock solution of $\mathrm{Pb}^{2+}$ was prepared using Lead nitrate $\left(\mathrm{PbNO}_{3}\right)$ in deionised water. Purified water was prepared using a Millipore Milli-Q (Bedford, MA, USA) water purification system. Standard solution of $\mathrm{Pb}^{2+}$ $(1000 \mathrm{mg} / \mathrm{L})$ for flame atomic absorption spectrometry analysis was obtained from Merck, Germany. $\mathrm{Pb}^{2+}$ solutions of different concentrations were obtained by diluting the stock solution. Standard acid of $0.1 \mathrm{M} \mathrm{HNO}_{3}$ and base solutions of $0.1 \mathrm{M} \mathrm{NaOH}$ were used for $\mathrm{pH}$ adjustments. 


\subsection{Preparation of Tea and Coffee Adsorbentss}

Exhausted coffee ground used was obtained from a local coffee manufacturer using steam extraction (Cerebos Greggs Ltd.). This material resulted from various coffee sources. The solid was dried in a stainless steel pan at $105^{\circ} \mathrm{C}$ for about 2 days to remove moisture, then ground and sieved through an ASTM 18 stainless steel sieve (1 $\mathrm{mm}$ mesh size). The solid was then repeated extracted with $0.1 \mathrm{M} \mathrm{NaOH}$ solution to remove soluble materials, neutralized with $0.1 \mathrm{M} \mathrm{HNO}_{3}$ and then rinsed extensively with deionized water base (Millipore Milli-Q) as reported earlier [6]. The material was then dried again at $105^{\circ} \mathrm{C}$ before ready to use for the batch experiment.

A Sri Lankan black tea variety known commercially as English Breakfast was obtained from a local supermarket. Tea leaves were removed from tea bags after Milli-Q pretreatment and drying at $105^{\circ} \mathrm{C}$ before being used as reported earlier [6].

\subsection{Batch Adsorption and Methods of Analysis}

Adsorption measurements were conducted by equilibrating $\mathrm{Pb}^{2+}$ solutions at different concentrations range 19$291 \mu \mathrm{mol} \cdot \mathrm{L}^{-1}$ with various adsorbent suspensions in the concentration range $0.388-8.738 \mathrm{~g} \cdot \mathrm{L}^{-1}$. Due to strong adsorptive properties found in preliminary experiment lower concentration of manganese dioxide $\left(\mathrm{MnO}_{2}\right)$ with range $0.388-1.214 \mathrm{~g} \cdot \mathrm{L}^{-1}$ was used rather than higher concentration range $2.913-8.738 \mathrm{~g} \cdot \mathrm{L}^{-1}$, which used for other adsorbents. Equilibration took place at room temperature $\left(21^{\circ} \mathrm{C}\right)$ using a rotating turntable overnight at 30 rpm. The suspensions were then filtered through a Whatman 114 filter and the concentrations of metal ion remaining in solution were determined by flame atomic absorption spectrometry using matrix-matched standards (Perkin Elmer AA 3100 series). From this the amount adsorbed was calculated by difference. For a given value of solid concentration $C_{s}$, the data were fitted to the Langmuir isotherm, Equation (2), using non linear leastsquares regression. This method, which differs from the more classical linearized fitting in a previous study, was carried out using the software NLReg [6] [12]. It involves varying the values of $K$ and $\Gamma_{m}$ from initial guesses until the sum of squared deviations of the calculated $\Gamma$ from the experimental value for each data point is minimized.

\section{Results and Discussions}

In most experiments each set of $\mathrm{Pb}^{2+}$ concentrations ranging from 19 to $291 \mu \mathrm{mol} \cdot \mathrm{L}^{-1}$ were equilibrated with 3 (three) different concentration of adsorbent $C_{s}$ except for coffee residue which used a wider range of concentration as detailed in Table 1.

More variations of coffee grounds concentration were used to clearly discuss a particle concentration effect found in this particular adsorption study. In this case coffee ground concentration used was extended from the concentrations of $0.971,2.913,4.369,5.825$ and $8.738 \mathrm{~g} \cdot \mathrm{L}^{-1}$. The result was expected in such cases that different concentrations of each adsorbent $C_{s}$ equilibrated with $\mathrm{Pb}^{2+}$ ranging from 19 to $291 \mu \mathrm{mol} \cdot \mathrm{L}^{-1}$ fit into a single Langmuir model, i.e. single values of $K$ and $\Gamma_{m}$ for each type of adsorbent.

Figure 1 shows the adsorption result at different $\mathrm{MnO}_{2}$ solid concentration $C_{s}$. The calculated curves of $\Gamma$ versus $C_{e}$ that resulted from this fitting are also shown in the figure. The curve was calculated using a fixed value of $K=0.0119 \mathrm{~L} \cdot \mu \mathrm{mol}^{-1}$ and a fixed value of $\Gamma_{m}=528.0 \mu \mathrm{mol} \mathrm{g}^{-1}$ for all $C_{s}$. The result shows that a single Langmuir equation adequately describes the data for the 3 different solid concentrations $C_{s}$. This implies that $\mathrm{Pb}^{2+}$ adsorption on $\mathrm{MnO}_{2}$ does obey the Langmuir Equation (2).

Adsorption of $\mathrm{Pb}^{2+}$ on GAC in aqueous solution was investigated using the procedure described above for $\mathrm{MnO}_{2}$ at the same concentration of solid $C_{\mathrm{s}}$ as used fortea leaves in the range $2.913-8.738 \mathrm{~g} \cdot \mathrm{L}^{-1}$. The result is shown in Figure 2 with the curve was calculated using a fixed value of $K=0.0158 \mathrm{~L} \cdot \mu \mathrm{mol}^{-1}$ and a fixed value of $\Gamma_{m}=134.0 \mu \mathrm{mol} \cdot \mathrm{g}^{-1}$ for all $C_{s}$. Again in this case, the results are reasonably well-described by a single Langmuir equation for different values of the solid concentrations $C_{s}$. This implies that $\mathrm{Pb}^{2+}$ adsorption on GAC does obey the Langmuir Equation (2).

Figure 3 shows the adsorption results for $\mathrm{Pb}^{2+}$ at different coffee solid concentrations $C_{s}$. The results are presented as the adsorption density $\Gamma$ as a function of the measured concentration of unadsorbed metal ion $C_{e}$. For a given value of solid concentration $C_{s}$, the data were fitted to the linearized form of Langmuir isotherm, Equation (2), using least-squares regression; the calculated curves are shown in the figure. Separate estimates of $K$ and $\Gamma_{m}$ values were obtained for each $C_{s}$ value, with results shown in Table 2. 


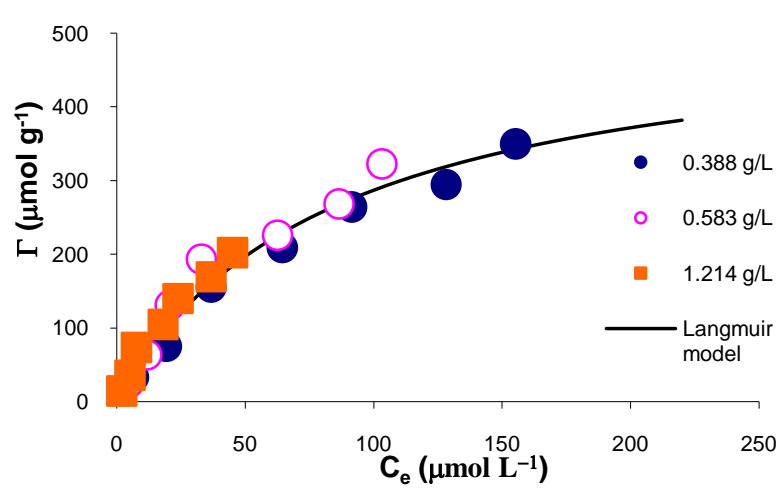

Figure 1. Adsorption density $\Gamma$ as a function of the measured equilibrium concentration $C_{e}$ of metal ion $\mathrm{Pb}^{2+}$ for 3 different concentrations of manganese dioxide $C_{s}$, i.e. $0.388,0.583$ and $1.214 \mathrm{~g} \cdot \mathrm{L}^{-1}$.

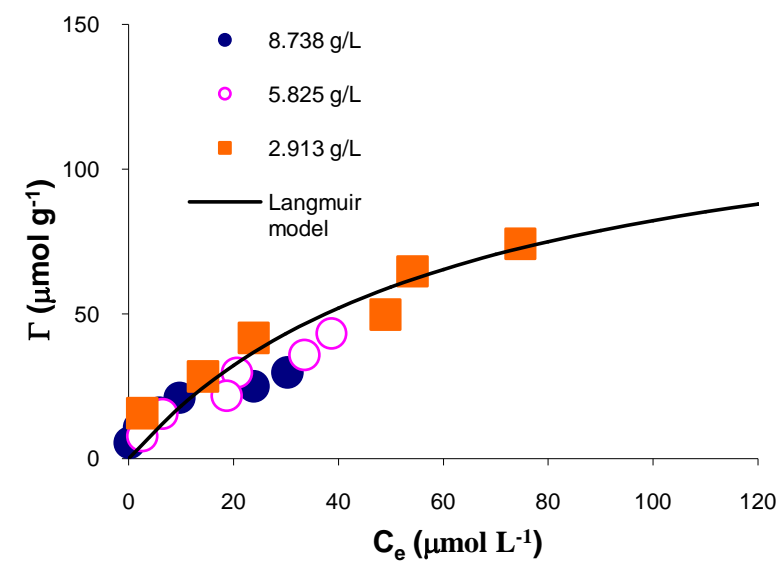

Figure 2. Adsorption density $\Gamma$ as a function of the measured equilibrium concentration $C_{e}$ of metal ion $\mathrm{Pb}^{2+}$ for 3 different concentrations of GAC $C_{s}$, i.e. $2.913,5.825$ and $8.738 \mathrm{~g} \cdot \mathrm{L}^{-1}$.

Table 1. Adsorbent concentration used to equilibrate $\mathrm{Pb}^{2+}$ solutions at concentrations range $19-291 \mu \mathrm{mol} \cdot \mathrm{L}^{-1}$.

\begin{tabular}{ccccc}
\hline \multicolumn{1}{c}{ Adsorbent } & GAC $\left(\mathrm{g} \cdot \mathrm{L}^{-1}\right)$ & Tea leaves $\left(\mathrm{g} \cdot \mathrm{L}^{-1}\right)$ & $\mathrm{MnO}_{2}\left(\mathrm{~g} \cdot \mathrm{L}^{-1}\right)$ & Coffee residue $\left(\mathrm{g} \cdot \mathrm{L}^{-1}\right)$ \\
\hline Concentration $\left(C_{s}\right)$ & $2.913,5.825,8.738$ & $2.913,5.825,8.738$ & $0.388,0.583,1.214$ & $0.971,2.913,4.369,5.825,8.738$ \\
\hline
\end{tabular}

Table 2. Adsorption results for $\mathrm{Pb}^{2+}$ at different solid concentrations $C_{s}$ for which separate estimates of $K$ and $\Gamma_{m}$ were obtained for each $C_{s}$ value [11]. The values in parentheses are the standard errors for each parameter obtained from the non-linear regression fitting.

\begin{tabular}{cccccc}
\hline \multirow{2}{*}{ Parameters } & \multicolumn{5}{c}{$C_{s}\left(\mathrm{~g} \cdot \mathrm{L}^{-1}\right)$} \\
\cline { 2 - 6 } & 0.971 & 2.913 & 4.369 & 5.825 & 8.738 \\
\hline$K\left(\mathrm{~L} \cdot \mu \mathrm{mol}^{-1}\right)$ & $0.0748(0.0069)$ & $0.0218(0.0040)$ & $0.0701(0.020)$ & $0.0284(0.0058)$ & $0.0310(0.0083)$ \\
$\Gamma\left(\mu \mathrm{mol} \cdot \mathrm{g}^{-1}\right)$ & $72.4(1.3)$ & $48.3(3.0)$ & $26.5(1.5)$ & $25.8(1.7)$ & $18.5(1.6)$ \\
\hline
\end{tabular}

The results shown in Figure 3 were very different from the previous two results, when using GAC and $\mathrm{MnO}_{2}$ as adsorbents. The results revealed that while the Langmuir Equation (2) adequately describes the adsorption equilibrium for a given $C_{s}$ value, the best-fit values of both $K$ and $\Gamma_{m}$ vary with $C_{s}$. This is not consistent with the simple Langmuir equation, which should give the same values of both parameters at different adsorbents concentrations. 


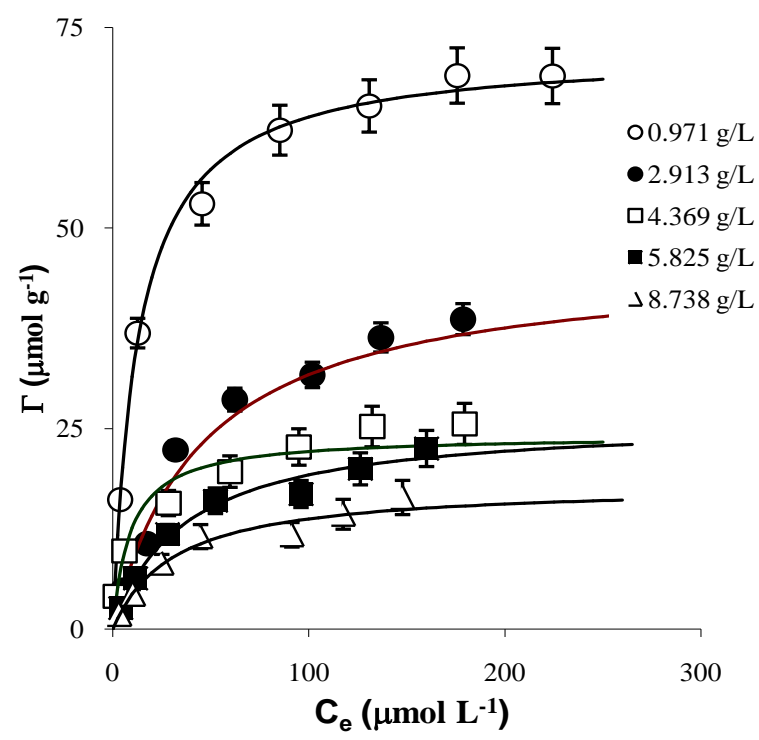

Figure 3. Adsorption density $\Gamma$ as a function of the measured equilibrium concentration $C_{e}$ of $\mathrm{Pb}^{2+}$ using five different concentrations of coffee solids $C_{s}$ ranging from 0.971 to $8.738 \mathrm{~g} \cdot \mathrm{L}^{-1}$. The curves were calculated using the separately-fitted Langmuir equation parameters $K$ and $\Gamma_{m}$ for each value of $C_{s}$. Error bars in this and subsequent figures represent the estimated uncertainties in $\Gamma$ based on the FAAS measurements of $\left[\mathrm{Pb}^{2+}\right][11]$.

A number of authors had reported that the parameters $K$ and/or $\Gamma_{m}$ could vary when measurements weremade at different concentrations of solid. Examples included quinoline adsorption by calcium montmorillonite [12], 2,2-bipyridine onto $\mathrm{Na}^{+}$-kaolinite [13], phosphate by hydrous aluminium oxides [14] and zinc by goethite [15] [16]. This dependence on $C_{s}$ violates the simple assumptions of the Langmuir theory.

Macchi [10] reported that the adsorption of $\mathrm{Hg}^{2+}$ by coffee grounds shows anomalous behaviour when the solids concentration $C_{s}$ is varied. However, they did not attribute this to an effect of $C_{s}$ on adsorption, but on the competitive effect of soluble organic substances leached out of the coffee. In fact the particle concentration effect on coffee grounds, when adsorbing heavy metal ions, was affected by particle aggregation [11].

The adsorption results using tea leaves adsorbent show different behaviour from that showed with coffee residue in Figure 3. There is very much less dependence of the adsorption curve on the concentration of solid. As shown in Figure 4, a single Langmuir model using fixed values of $K=0.0119 \mathrm{~L} \cdot \mu \mathrm{mol}^{-1}$ and $\Gamma_{m}=5.0$

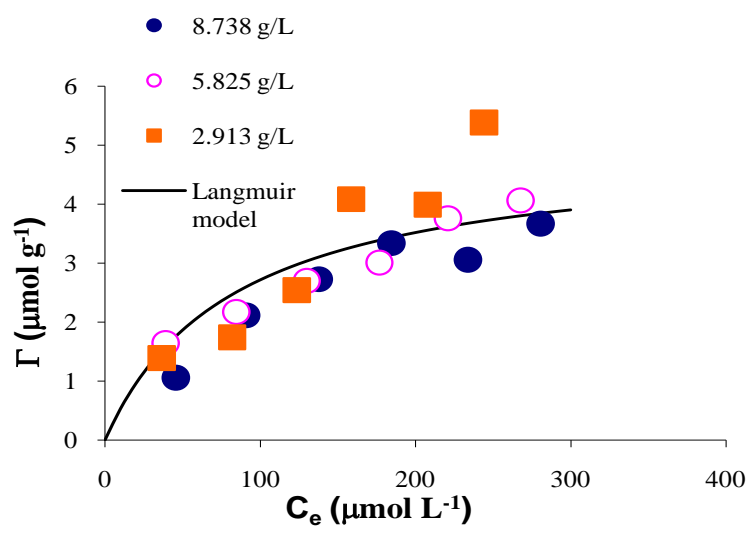

Figure 4. Adsorption density $\Gamma$ as a function of the measured equilibrium concentration $C_{e}$ of $\mathrm{Pb}^{2+}$ for 3 different concentrations of tea leaves $C_{s}$, i.e. $2.913,5.825$ and $8.738 \mathrm{~g} \cdot \mathrm{L}^{-1}$. 
$\mu \mathrm{mol} \cdot \mathrm{g}^{-1}$ for all $C_{s}$ values fitted the data reasonably well, given the scatter of the points at $2.913 \mathrm{~g} / \mathrm{L}$. This suggests that lead adsorption on tea leaves approximately follows the simple Langmuir equation.

\section{Conclusions}

$\mathrm{Pb}^{2+}$ adsorption at low concentration onto various solid surfaces using either nano metal oxide of $\mathrm{MnO}_{2}$, or granulated activated carbon (GAC) or agricultural by-products such as tea leaves and coffee residue is unarguably promising.

Comparing all the adsorption capacities calculated using single Langmuir equation the $\mathrm{Pb}^{2+}$ adsorption using nano metal oxide of $\mathrm{MnO}_{2}$ shows the highest adsorption capacity with the estimated $\Gamma_{m}=528.0 \mu \mathrm{mol} \cdot \mathrm{g}^{-1} \mathrm{at} \mathrm{a}$ fixed equilibrium constant $K=0.0119 \mathrm{~L} \cdot \mu \mathrm{mol}^{-1}$. This could be due to the largest surface area per mass of $\mathrm{MnO}_{2}$.

The $\mathrm{Pb}^{2+}$ adsorption by coffee residue is subject to "particle concentration effect" in which the adsorption density decreases as the concentration of solid adsorbent $C_{s}$ is increased. The $\mathrm{Pb}^{2+}$ adsorption onto tea leaves, $\mathrm{MnO}_{2}$ and GAC shows less dependency to the concentration of solid adsorbent $C_{s}$, especially at lower metal ion concentrations. In the particular case of $\mathrm{Pb}^{2+}$ adsorption on $\mathrm{MnO}_{2}$ there appears to be no dependence on $C_{s}$ and the single Langmuir equation is followed.

\section{Acknowledgements}

The laboratory experiment was conducted at Marine and Freshwater Chemistry Laboratory, University of Otago, New Zealand where the author was receiving the University of Otago, Division of Science Award. Preparation of manuscript writing and presentation was supported by Singapore Polytechnic (TIEFA) Vote Number: 1127801-36-R185. The author acknowledged Professor Keith A. Hunter for his assistance in developing the nonlinear Langmuir isotherm model using NLReg special software.

\section{References}

[1] Alloway, B.J. and Ayres, D.C. (1993) Chemical Principles of Environmental Pollution. Blackie Academic and Professional, London. http://dx.doi.org/10.1007/978-94-011-2148-4

[2] US Environmental Protection Agency (2001) Lead: Identification of Dangerous Levels of Lead: Final Rule. US Government Printing Office, Washington DC.

[3] US Environmental Protection Agency (2001) Identifying Lead Hazards in Residential Properties. EPA 747/F-01/002, US Government Printing Office, Washington DC.

[4] Bailey, S.E., Olin, T.J., et al. (1999) A Review of Potentially Low-Cost Sorbents for Heavy Metals. Water Research, 33, 2469-2479. http://dx.doi.org/10.1016/S0043-1354(98)00475-8

[5] Low, K.S., Lee, C.K., et al. (2000) Metalsoprtion Enhancement of Rice Hull through Chemical Modification. Environmental Technology, 21, 1239-1243. http://dx.doi.org/10.1080/09593332108618152

[6] Djati Utomo, H. and Hunter, K.A. (2006) Adsorption of Divalent Copper, Zinc, Cadmium and Lead Ions from Aqueous Solution by Waste Tea and Coffee Adsorbents. Journal of Environmental Technology, 27, 25-32. http://dx.doi.org/10.1080/09593332708618619

[7] Hawken, P. (2000) Reframing the Sustainability Debate. Specialty Coffee Association of America Conference, San Francisco.

[8] Orhan, Y. and Buyukgungor, H. (1993) The Removal of Heavy-Metals by Using Agricultural Wastes. Water Science and Technology, 28, 247-255.

[9] Tan, W.T. (1985) Copper (II) Adsorption by Waste Tea Leaves and Coffee Powder. Pertanika, 8, $223-230$.

[10] Macchi, G., Marani, D., et al. (1986) Uptake of Mercury by Exhausted Coffee Grounds. Environmental Technology Letters, 7, 431-444.

[11] Djati Utomo, H. and Hunter, K.A. (2010) Particle Concentration Effect: Adsorption of Divalent Metal Ions on Coffee Grounds. Bioresource Technology, 101, 1482-1486. http://dx.doi.org/10.1016/j.biortech.2009.06.094

[12] Sherrod, P.H. (1992) NONLIN Manual. Nashville.

[13] De Bussetti, S.G. and Ferreiro, E.A. (2005) Effect on 2,2-Bipyridine Adsorption of Poly(Vinyl Alcohol) Adsorbed on $\mathrm{Na}^{+}$-Kaolinite. Applied Clay Science, 29, 207-214.

[14] Ferreiro, E.A., Debussetti, S.G., et al. (1992) Effect of Montmorillonite on Phosphate Sorption by Hydrous Al-Oxides. Geoderma, 55, 111-118. 
[15] Pan, G. and Liss, P.S. (1998) Metastable-Equilibrium Adsorption Theory. I. Theoretical. Journal of Colloid and Interface Science, 201, 71-76. http://dx.doi.org/10.1006/jcis.1998.5396

[16] Pan, G. and Liss, P.S. (1998) Metastable-Equilibrium Adsorption Theory. II. Experimental. Journal of Colloid and Interface Science, 201, 77-85. http://dx.doi.org/10.1006/jcis.1998.5397 